\title{
睡眠時無呼吸症候群における鼻腔抵抗值の体位変化
}

1 ) 名古屋大学大学院耳鼻咽喉科・頭頸部外科学教室

3 ) 滋賀医科大学睡眠学講座

5 ) 藤田保健衛生大学耳鼻咽喉科学教室

7 ) 鳥取大学医学部耳鼻咽喉科学教室

9 ) 三重大学医学部耳鼻咽喉科教室

中田誠—11, 川野和弘 ${ }^{21}$, 岡 本 牧 人 ${ }^{4)}$, 内藤 健 晴 ${ }^{5}$,

竹内 裕 美 $^{7)}$ 千葉 伸太郎 ${ }^{8)}$,

\author{
2 ) 東邦大学第 2 耳鼻咽喉科学教室 \\ 4 ) 北里大学耳鼻咽喉科学教室 \\ 6 ) 旭川医科大学耳鼻咽喉科学教室 \\ 8 ）太田総合病院耳鼻咽喉科
}

大末 幹 文 ${ }^{2)}$, 宮崎 総一郎 ${ }^{3)}$, 野中聡6), 樋上茂 ${ }^{7)}$, 竹内 万彦年, 間島 雄 -99

\section{Postural Variations of Nasal Resistance in Patient with Sleep Apnea Syndrome}

\author{
Seiichi Nakata ${ }^{1)}$, Ohki Motofumi ${ }^{2)}$, Soichiro Miyazaki ${ }^{3)}$, \\ Makito Okamoto ${ }^{4)}$, Kensei Naito ${ }^{5)}$, Satoshi Nonaka ${ }^{6)}$, \\ Hiromi Takeuchi ${ }^{7}$, Shintaro $\mathrm{Chiba}^{8)}$, Kazuhiro Kawano ${ }^{2)}$, \\ Shigeru Higami ${ }^{7)}$, Kazuhiko Takeuchi9), Yuichi Majima"
}

\footnotetext{
${ }^{1)}$ Department of Otorhinolaryngology, Nagoya University Graduate School of Medicine, Nagoya

${ }^{2)}$ Second Department of Otorhinolaryngology, Toho University School of Medicine, Tokyo

${ }^{3)}$ Department of Sleep Medicine, Shiga Medical College, Shiga

${ }^{4)}$ Department of Otolaryngology, Kitazato University School of Medicine, Kanagawa

${ }^{5}$ Department of Otolaryngology, Fujita Health University School of Medicine, Aichi

${ }^{6}$ Department of Otolaryngology-Head and Neck Surgery, Asahikawa Medical College, Asahikawa

${ }^{7)}$ Department of Otorhinolaryngology, Faculty of Medicine, Tottori University, Yonago

${ }^{8)}$ Department of Otorhinolaryngology, Ohta General Hospital, Kawasaki

${ }^{9}$ Department of Otorhinolaryngology, Mie University School of Medicine, Mie
}

Total and unilateral nasal resistance in 48 patients with sleep apnea syndrome (SAS) and 35 normal subjects were compared upright and supinely to determine the importance of nasal resistnce in supine SAS patients. Active anterior rhinomanometry was conducted with a Nippon Kohden MPR-3100 rhinomanometer to measure unilateral (inspiratory and expiratory) and total (inspiratory and expiratory) nasal resistance.

Total (both expiratory $(\Delta 100 \mathrm{~Pa}$ and $\Delta 150 \mathrm{~Pa})$ and inspiratory $(\Delta 100 \mathrm{~Pa}))$ nasal resistance in normal subjects increase more significantly in supine than upright subjects. Total inspiratory $(\Delta 100 \mathrm{~Pa})$ nasal resistance in SAS patients increases more significantly in supine than upright patients. No correlation was seen between BMI and increasing nasal resistance in changing from supine to upright in normal subjects and SAS patients.

In conclusion, when measuring nasal resistance in SAS patients, the supine position which is closer to sleeping condition, may be more suitable than upright.

Key words：鼻腔抵抗値，睡眠時無呼吸症候群，体位変化，鼻腔通気度検查，鼻閉 


\section{はじめに}

鼻腔通気度検査は鼻・副鼻腔疾患の診断と治療の評価 に広く用いられ ${ }^{1,2,3)}$ ，鼻閉を他覚的かつ客観的に評伍で きる優れた検査法4) ではあるが，時に鼻閉感と鼻腔抵抗 值が乘離する場合がある5)。また, 睡眠時無呼吸症候群 (Sleep Apnea Syndrome 以下 SAS) は, 鼻閉を伴うと増 悪し ${ }^{6)}$ ，鼻閉を改善することによって SAS も時に劇的に 改善する7)ことが知られている。しかるに鼻腔抵抗値が SAS にどのように関与するかは現在余り知られていな い。今回我々は, 鼻閉感と鼻腔抵抗值が乘離する場合の 一原因として, 通常計測している座位での鼻腔抵抗攸が 睡眠中の鼻腔抵抗を反映していないのではないかと考 え, 特に鼻閉感なく鼻疾患のない成人と OSAS 患者にお いて，それぞれ座位，仰臥位15分後で鼻腔抵抗值がどの ように変化したかを比較検討した。

\section{対象と方法}

本研究では, マルチセンタースタディにより，20墄か ら59歳までの鼻閉なく鼻疾患のない正常成人 35 名（平均 年齢 $36.3 \pm 10.4$ 歳 $)$, 夜間ポリソムノグラフ検查: で
$\mathrm{AHI}>10 / \mathrm{hr}$.またはパルソックス（パルスオキシメータ 一, コニカミノルタセンシング社）にて ODI $3 \%>$ 10/hr. を睡眠時無呼吸症候群と定義し，その定義に合致 した48例（51.4 10.4歳）を対象とした。それら 2 群に て, 正常成人群は, 座位, 仰臥位 15 分後での $100 \mathrm{~Pa}, 150$ $\mathrm{Pa}$ での片側, 両側鼻腔抵抗值を, SAS 症例群は $100 \mathrm{~Pa}$ での片側, 両側鼻腔抵抗值をそれぞれ計測した。鼻腔通 気度測定機器は全例, 日本光電社製 MPR-3100を使い ノズル・アクテイブ・アンテリオール法で左右片側測定 を行い，抵抗值を算出した。両側鼻腔抵抗値は左右の片 側抵抗よりオームの法則に従って計算式 $(1 / \mathrm{T}=1 / \mathrm{R}+$ $1 / \mathrm{L}) （ \mathrm{~T}$ : 両側鼻腔抵抗, $\mathrm{R}$ : 右側抵抗, $\mathrm{L}$ ：左側抵 抗）により算出された。検定は student- $\mathrm{t}$ 検定を用い $5 \%$ 以下を有意水準とした。

\section{結果}

鼻閉なく鼻疾患のない正常成人群 35 名の内訳は身長 $170.3 \pm 6.1 \mathrm{~cm}$, 体重 $66.5 \pm 8.3 \mathrm{~kg}$ であり, 一方 SAS 群 48 名は身長 $168.1 \pm 7.4 \mathrm{~cm}$, 体重 $79.7 \pm 18.1 \mathrm{~kg}$ であっ た。

表 1 に示すように両側鼻腔抵抗值は正常群の $100 \mathrm{~Pa}$

表 1 正常成人における鼻腔抵抗値計測結果

\begin{tabular}{ll}
\multicolumn{2}{l}{ 正常成人群 } \\
例数 & 35 例 \\
年齢 & $36.3 \pm 10.4$ \\
身長 & $170.3 \pm 6.1 \mathrm{~cm}$ \\
体重 & $66.5 \pm 8.3 \mathrm{~kg}$
\end{tabular}

鼻腔抵抗値の単位は全て $\mathrm{Pa} / \mathrm{cm}^{3} / \mathrm{sec}$

\begin{tabular}{|c|c|c|c|c|}
\hline 座位右100呼 & $0.57 \pm 0.24$ & 臥位右100呼 & $0.77 \pm 0.58$ & $\mathrm{p}=0.0320$ \\
\hline 座位右 100 吸 & $0.46 \pm 0.20$ & 臥位右 100 吸 & $0.70 \pm 0.50$ & $\mathrm{p}=0.0055$ \\
\hline 座位左100呼 & $0.67 \pm 0.48$ & 臥位左100呼 & $1.03 \pm 2.08$ & $\mathrm{p}=0.2815$ \\
\hline 座位左100吸 & $0.61 \pm 0.43$ & 臥位左100吸 & $0.99 \pm 1.74$ & $p=0.0609$ \\
\hline 座位右150呼 & $0.64 \pm 0.23$ & 臥位右150呼 & $0.79 \pm 0.45$ & $\mathrm{p}=0.0338$ \\
\hline 座位右150吸 & $0.53 \pm 0.22$ & 臥位右150吸 & $0.78 \pm 0.48$ & $\mathrm{p}=0.0420$ \\
\hline 座位左150呼 & $0.72 \pm 0.49$ & 臥位左150呼 & $1.09 \pm 2.06$ & $\mathrm{p}=0.2910$ \\
\hline 座位左150吸 & $0.71 \pm 0.49$ & 臥位左150吸 & $1.71 \pm 5.28$ & $\mathrm{p}=0.2649$ \\
\hline 座位両100呼 & $0.28 \pm 0.13$ & 臥位両100呼 & $0.30 \pm 0.16$ & $\mathrm{p}=0.0742$ \\
\hline 座位両100吸 & $0.23 \pm 0.09$ & 臥位両100吸 & $0.30 \pm 0.14$ & $\mathrm{p}=0.0070$ \\
\hline 座位両150呼 & $0.30 \pm 0.11$ & 臥位両150呼 & $0.36 \pm 0.18$ & $\mathrm{p}=0.0211$ \\
\hline 座位両150吸 & $0.27 \pm 0.11$ & 臥位両150吸 & $0.33 \pm 0.15$ & $\mathrm{p}=0.0234$ \\
\hline 略字説明 & 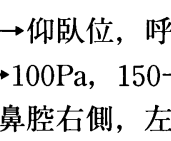 & $\begin{array}{l}\text { 乎気時, 吸 } \rightarrow \\
0 \mathrm{~Pa} \\
\mathrm{~g}_{1} \text { 腔左側 }\end{array}$ & & \\
\hline
\end{tabular}


表 2 睡眠時無呼吸症候群患者における鼻腔抵抗值計測結果

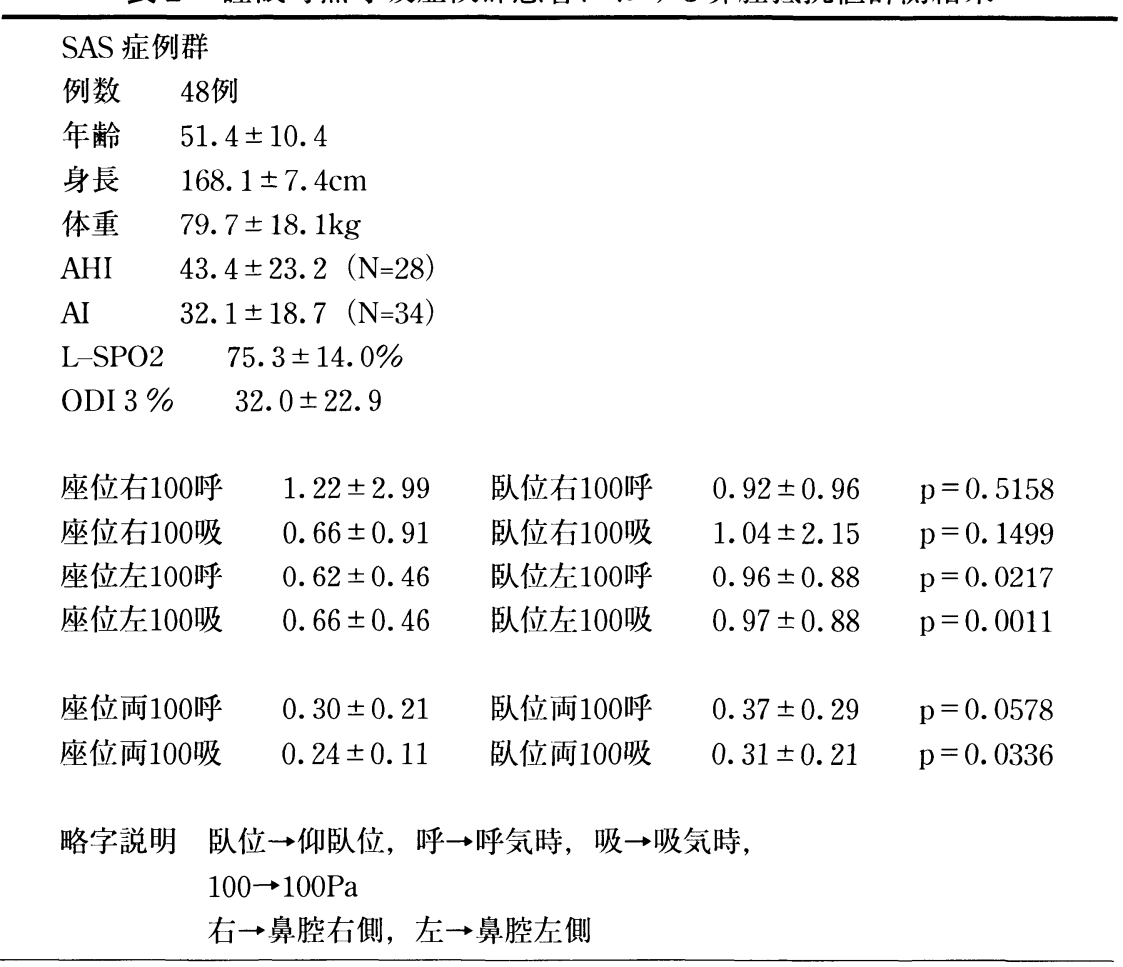

の吸気時, $150 \mathrm{~Pa}$ の呼気時, 吸気時とも有意に, 座位か ら仰臥位になると鼻腔抵抗值が上昇する傾向を認めた。 一方, SAS 群の両側鼻腔抵抗值は $100 \mathrm{~Pa}$ において吸気 時においては座位から仰臥位になると鼻腔抵抗值が有意 差を持って上昇したが，呼気時は有意差を認めず（座位 両側 $100 \mathrm{~Pa}$ 呼気時 $0.30 \pm 0.21 \mathrm{~Pa} / \mathrm{cm}^{3} / \mathrm{sec}$ 臥位両側 100 $\mathrm{Pa}$ 呼気時 $\left.0.37 \pm 0.29 \mathrm{~Pa} / \mathrm{cm}^{3} / \mathrm{sec} \mathrm{p}=0.0578\right)$, 平均值 が上昇したのみであった（表 2$)$ 。片側鼻腔抵抗值は正 常成人において $100 \mathrm{~Pa}, 150 \mathrm{~Pa}$ 共, 右側の吸気, 呼気時 において座位から仰臥位になると鼻腔抵抗值が有意差を 持って上昇したが左側はそれを認めなかった（表 1 )。

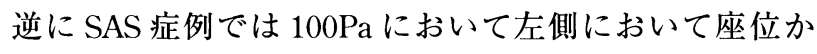
ら仰臥位になると鼻腔抵抗值が有意差を持って上昇した が右側はそれを認めなかった（表 2 ）。

座位から仰臥位に体位変換したとき，鼻腔抵抗值がど のように変化するかの割合いは正常症例においては増加 (仰臥位の抵抗値>座位の抵抗値) $66 \%(23 / 35)$, 不変 $23 \%(8 / 23)$, 低下（座位の抵抗值>仰臥位の抵抗值）

11\%(4/35) であり, SAS 症例においては増加 $79 \%$ $(38 / 48)$, 不変 $4 \%(2 / 48)$, 低下 $17 \%(8 / 48)$ であっ た。両例においても増加の割合は $60 \%$ 以上を占め, 低下 は20\%以下であった（表 3 )。又，これら正常症例と SAS 症例においての体位変化時の鼻腔抵抗值変化度 は， 2 群間に有意の差を認めなかった。

さらに SAS 症例において BMI と座位から仰卧位に変
表 3 体位変化時 (座位 $\rightarrow$ 仰臥位) における鼻腔抵抗値 (両 側 $\triangle \mathrm{P} 100 \mathrm{~Pa}$ )

\begin{tabular}{|c|c|c|}
\hline \multicolumn{3}{|c|}{ SAS 症例（全48例） } \\
\hline 増加 & 38例（完全鼻閉にて計測不能は 4 例） & $79 \%$ \\
\hline 不変 & 2例 & $4 \%$ \\
\hline 低下 & 8例 & $17 \%$ \\
\hline \multicolumn{3}{|c|}{ 正常症例（全35例） } \\
\hline 増加 & 23例（完全鼻閉にて計測不能は 4 例） & $66 \%$ \\
\hline 不変 & 8 例 & $23 \%$ \\
\hline 低下 & 4例 & $11 \%$ \\
\hline
\end{tabular}

換したときの鼻腔抵抗值の上昇度 ( $\Delta$ P100P の両側鼻 腔抵抗值）は図 1 のように決定係数が 0.102 となり明ら かな相関関係は認めなかった。

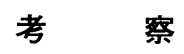

鼻閉はSAS の原因とも成り得る。正常小児に鼻閉を 起こさせると, 著明な上気抵抗増加を伴った低換気また は周期的な無呼吸が起こり ${ }^{8)}$, 成人においても鼻栓によ りほとんど 0 であった無呼吸低呼吸指数が最高10にまで 及ぶ9)。一方, SASにおいての鼻閉の関与は幾多の方面 に及ぶ。鼻閉が増せば, より気道が陰圧となり気道内圧 が増し，ひいては肺胞低換気にまで及ぶ10) といった説や 正常成人より, 鼻閉によるSASの患者は覚醒（脳波上 覚醒波の出現〔 $\alpha$ 波や $\beta$ 波〕もしくは脳波上明らかに浅 


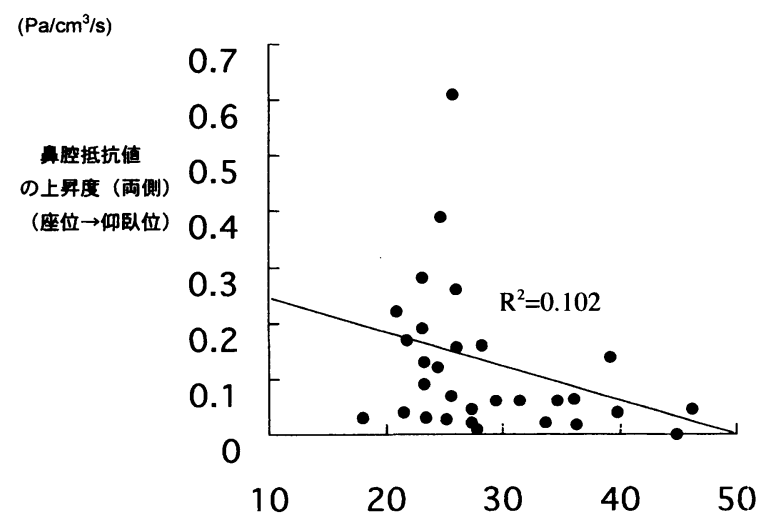

図 1 BMI と鼻腔抵抗值の上昇度（座位 $\rightarrow$ 仰臥位への） 体位変換時）との相関

い睡眠相への移行が 3 秒以上持続した場合）が多いとの 報告 ${ }^{11)}$ もる。このように鼻閉は正常成人においても無 呼吸を起こす原因ともなりうる可能性もあり,さらに SASの人においてはさらに増悪させる因子でもある。 又, 一方, 鼻閉が強くなれば鼻呼吸から口呼吸への移行 が見られ，この状態が舌根沈下へとつながり無呼吸低呼 吸状態を惹起または増悪させることが予想される。Cole らは鼻呼吸から口呼吸へと移行する鼻腔抵抗値として $0.5 \mathrm{~Pa} / \mathrm{cm}^{3} / \mathrm{sec}$ を目安としている ${ }^{12)}$ 。このよう鼻閉を 客観的に示す数值が鼻腔通気度ではあるが, その鼻閉を 人が自覚する鼻閉感はきわめて曖昧で時には乘離が認め られる ${ }^{5)}$ 。とはいえ, 患者が自覚する慢性の鼻閉感と鼻 腔抵抗は日本人の場合, おおむね良好な比例関係を示す と言われている ${ }^{13)}$ 。

鼻腔抵抗值の体位変化に拉いては, Hasegawaらの報 告によると健常者15名を座位から仰臥位まで30度ずつ頭 位を下げてゆくと鼻腔抵抗值はわずかながら上昇す る ${ }^{14)}$ 。今回, 我々は, 正常成人, SAS 症例ともに座位吕 ら仰臥位に変換したとき両側の鼻腔抵抗值は吸気時にお いては有意に上昇し, 呼気時においても同様の傾向が認 められた。かつ正常例, SAS 症例においても体位変換時 に $60 \%$ 以上に鼻腔抵抗值の上昇と $20 \%$ 以下の鼻腔抵抗值 の低下を認めた。吸気時の方が呼気時に比べて, 体位変 化における鼻腔抵抗値の変化がより著明に表れたのは, 吸気時の陰圧により鼻腔内の虚脱が発生し, それが仰卧 位では重力も加わりより明確になったためではないかと 考える。又, SAS 群での体位変換時の鼻腔抵抗值が増加 するメカニズムは, 仰臥位になると上咽頭軟部組織が腫

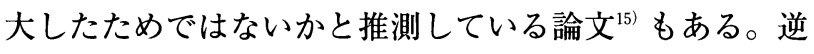
に体位変換時の鼻腔抵抗值の低下は, Altissimi らによっ ても指摘されており,これらの原因として交感神経の関 与が考えられるが, どのようなメカニズムで関与してい
るのかは今後の検討課題としている ${ }^{16)}$ 。又, 座位から仰 臥位になるとき片側鼻腔抵抗值の有意差が左右で分れる といった結果が出ている。これらは “nasal cycle” ${ }^{17)}$ が 密接に関連しているとは思われるがこれらのメカニズム 解明も今後のさらなる研究に期待したい。

鼻腔抵抗值と体重の関係については相関関係はないと いう報告があり ${ }^{18)}$, 今回, BMI と体位変換時の鼻腔抵抗 値の変化について着目したが, 同様に明らかな相関関係 は認めなかった。かつ平均体重が $66.5 \pm 8.3 \mathrm{~kg}$ の正常 例と平均体重が $79.7 \pm 18.1 \mathrm{~kg}$ の SAS 例の体位変換時に おける鼻腔抵抗值の変化度においても有意な差がないこ とから，体重を増すことが鼻腔抵抗値に及ぼす影響は少 ないと推察された。しかし BMI が増せば鼻腔抵抗值が 増加するといった報告 ${ }^{19)}$ もあり，さらなる検討を要する と思われる。

以上より, 正常成人同様, SAS 患者においても座位の 鼻腔抵抗より睡眠時における仰臥位の鼻腔抵抗のほうが 確率的に高くなると考えられ，座位鼻腔抵抗值がそれほ ど高くない人でも夜間時鼻閉のため無呼吸が増加した り, 経鼻持続陽圧呼吸療法 (nasal Continuous Positive Airway Pressure nCPAP) が使えない場合も推察され る。よって SAS 患者の鼻腔抵抗值を計測する際, 無呼 吸が起きている夜間の仰臥している状態を考え, 睡眠時 により状態の近い仰臥位15分後の鼻腔通気度検査の方が 座位での同検査よりもより実情に即した検査であると考 える。

\section{ま と め}

1. 正常症例においては片側では右側 $\Delta \mathrm{P} 100 \mathrm{~Pa}$ 時 (呼気, 吸気共), 両側では吸気時 $\Delta \mathrm{P} 100 \mathrm{~Pa}$ 時において 座位から仰臥位15分後の変換での鼻腔抵抗值に有意の上 昇が見られた。

2. SAS 症例においては片側では左側 $\Delta \mathrm{P} 100 \mathrm{~Pa}$ 時 (呼気, 吸気共), 雨側では吸気時 $\triangle \mathrm{P} 100 \mathrm{~Pa}$ 時において 座位から仰臥位15分後の変換での鼻腔抵抗値に有意の上 昇が見られた。

3. BMI と鼻腔抵抗值の上昇值（座位 $\Rightarrow$ 仰臥位15分） に相関関係は認めなかった。

4. SAS 患者の鼻腔抵抗值を計測する際，睡眠時によ り状態の近い仰臥位15分後の鼻腔通気度検查の方が座位 での同検查よりもより実情に即した検査であると考え る。

\section{文献}

1 ）宮崎総一郎, 板坂芳明, 石川和夫, 他：鼻腔通気度 
検查の実施状況一全国アンケート調査結果一。耳鼻 臨床 補：98-101，1997.

2 ）臼井信郎, 川野和弘：気流抵抗検査による閉塞性睡 眠時無呼吸症候群の手術適応基準。口咽科 10： 191-199, 1998.

3 ）大木幹文: 鼻腔通気度の国内外の比較. 日鼻誌 29 :247-253, 1991.

4) Mccaffrey TV : Rhinomanometry : Functional assessment of the nasal airway. In Otolaryngology, English GM (ed), Lippincot-Raven, Philadelphia : pp1-12, 1994.

5 ）内藤健晴：鼻閉の客観化に関する研究の進歩. 耳喉 頭頸 72:479-488, 2000.

6 ) Taasan V, Wynne JW, Cassisi N, et al: The effect of nasal packing on sleep-disordered breathing and nocturnal oxygen desaturation. Laryngoscope 91 : 1163-1172, 1981.

7 ) Heimer D, Scharf SM, Liberman A, et al : Sleep apnea syndrome treated by repair of deviated nasal septum. Chest 84 : 184-185, 1983.

8 ) Konno A, Togawa K, Hoshino T: The effect of nasal obstruction in infancy and early childhood upon ventilation. Laryngoscope 90 : 699-707, 1980.

9 ) Olsen KD, Kern EB, Westbrook PR: Sleep and breathing disturbance secondary to nasal obstruction. Otolaryngol Head Neck Surg 89: 804-810, 1981.

10) Papsidero $\mathrm{MJ}$ : The role of nasal obstruction in obstructive sleep apnea syndrome. Ear Nose Throat J 72 : 82-84, 1993.

11) Lavie P, Gerter R, Zomer J, et al : Breathing Disor- ders in sleep associated with "microarousals" in patients with allergic rhinitis. Acta Otolaryngol 92 : 529-533, 1981.

12) Cole $\mathrm{P}$ : The respiratory role of the upper airways. Mosby Year Book, St Lous, 1993.

13) Naito K, Kondo $Y$, Ohoka E, et al : New aerodynamic aspects of nasal patency Rhinology $33: 26^{-}$ 29, 1955.

14) Hasegawa $M$, Saito $Y$ : Postural variations in nasal resistance and symptomatology in allergic rhinitis. Acta Otolaryngol 88 : 268-272, 1979.

15）中野勇治, 朝倉光司 : 閉塞型睡眠時無呼吸症候群の 鼻腔抵抗。耳鼻臨床 83(9)：1429-1434，1990.

16) Altissmi G, Gallucci L, Rossetti M, et al : Diagnosing nasal hyperactivity with positional rhinomanometry. Ann Otol Rhinol Laryngol 105 : 901-904, 1996.

17) Kayser R: Die exacte Messung der Luftdurchgangigkeit der Nase. Arch Laryngol 3: 101-120, 1895.

18) Gammert C, Hampl K, Herrmann $P$ : Normal values in rhinomanometry. HNO 36(10) : 399-405, 1988.

19) Crouse U, Laine-- Alava MT: Effects of age, body mass index, and gender on nasal airflow rate and pressures. Laryngoscope 109: 1503-1508, 1999.

（2004年 9 月 21 日受稿， 2004年10月21日受理）

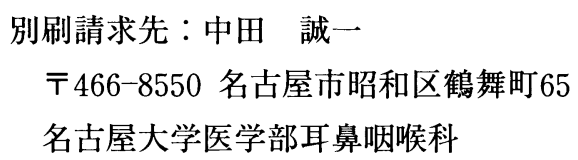

Tel : 052-744-2323 Fax :052-744-2325 